\title{
Differences in Risk Preferences of the Main Ethnic Groups in Peninsular Malaysia: A Field Experiment
}

\author{
Kean-Siang Ch'ng ${ }^{\mathrm{a}}$ \\ Suresh Narayanan ${ }^{b}$ \\ Universiti Sains Malaysia
}

\begin{abstract}
It is widely held that risk preferences differ between the three ethnic groups in Malaysia with the Chinese having the highest preference for risk and Malays having the lowest. This has been used to explain the Chinese preference for, and success in, business ventures relative to Malays. However, this assumption has never been tested in a controlled environment. Three hundred working adults from the three groups were recruited and participated in two-choice lottery games with real monetary reward and risk. The results were analysed using the framework of cumulative prospect theory. The outcomes indicate that broad generalisations regarding inter-ethnic risk tolerance are inaccurate. Malays were less risk averse than the Chinese or others when facing choices with the possibility of losing but became more risk averse only when facing choices with the possibility of winning. Malays were also more willing to take greater risk to reduce possible loss than to settle for a sure gain, compared to the others.
\end{abstract}

Keywords: Ethnic groups, field experiment, Malaysia, risk preferences JEL classification: C93, D03, D81

\section{Introduction}

The ethnically diverse population of Peninsular Malaysia comprises of Malays, Chinese, Indians and others. In 2016, the three main groups accounted for 66 percent, 25 percent and 8.5 percent of the population, respectively ${ }^{1}$. There are some reasons to expect that there might be differences in their attitudes to risk. Ethnic Chinese and Indians in Malaysia are of immigrant background, though differences exist in the manner in which their forebears came to this country. The former were largely voluntary migrants (Jackson, 1961) while the bulk of the early Indians were recruited from South India via two widely abused recruitment systems that combined false promises with coercion (Satyanarayana, 2002). Voluntary migrants have been found to not only be risk tolerant but individual risk attitudes of migrants were found to be unaffected by substantial

a Economics Department, School of Social Sciences, Universiti Sains Malaysia, 11800 USM Penang, Malaysia. Email:cks@usm.my (Corresponding author)

b Economics Department, School of Social Sciences, Universiti Sains Malaysia, 11800 USM Penang, Malaysia. Email:nsuresh@usm.my

* This research project was funded by a Fundamental Research Grant (No: 03.PSOSIAL.6711416) under the Pengajian Pendidikan Tinggi Scheme, Malaysia.

1 http://pqi.stats.gov.my/searchBI.php 
changes in the environment. Furthermore, the risk tolerance was correlated across generations (Akgüç, Lui, Tani, \& Zimmermann, 2016). However, we might expect to find less of these traits among the ethnic Indians, given their recruitment mechanisms. The Malays, on the other hand, are Muslims and Islam forbids gambling. Thus religious beliefs or religiosity can be a reason why we might expect ethnic differences in risk attitudes (Nielsen, Christensen, Kiil, \& Hvidt, 2017). As opposed to this, one must consider the fact that Malays enjoy constitutionally-guaranteed privileges (Lai, Chong, Sia, \& Ooi, 2010) and a high proportion of them are employed in the public sector with its job security and generous pensions. This 'insurance' might well motivate Malays to be more, rather than less, risk-tolerant since losses will not mean the loss of employment or pension. This is an outcome suggested by the moral hazard argument.

While differences in risk tolerance among ethnic groups may be expected, no study has directly investigated if these differences exist, and their nature, if they do. This paper is an attempt to fill the gap. We investigate the risk evaluation patterns among the three main ethnic groups - Malay, Chinese and Indian - in Peninsular Malaysia. More specifically, we look at how risk is perceived or evaluated by the members drawn from these ethnic groups.

\section{Conceptual Framework}

To understand the differences in risk preferences among the main ethnic groups in Malaysia, we implemented a two-choice lottery game, in which subjects had to reveal their true risk preferences when real monetary reward and risk were involved. In the two-choice lottery game, subjects could choose either a lottery or a guaranteed payoff. The outcome was used to investigate the four-fold pattern of risk, probability weighting and outcomes evaluation of the three major ethnic groups. This would reveal if different risk preferences exist among them and if it might be a possible factor in the unequal income distribution along ethnic lines.

Decision making on risk outcomes/prospects often deviates from the prediction based on expected utility (EU) theory and alternative models have been proposed (Starmer, 2000; Starmer \& Sugden, 1989). One widely accepted model is the cumulative prospect theory (CPT) proposed by Tversky and Kahneman (1992), who made two notable observations: first, individuals were risk-seeking over a gain domain and riskaverse over a loss domain. Second, individuals tend to overweight low probability events and underweight high probability events. Emerging from these observations is the four-fold pattern of risk in which individuals become (1) risk-seeking over low probability gains, (2) risk-averse over high probability gains, (3) risk-averse over low probability losses and (4) risk-seeking over high probability losses.

The first observation that individuals were risk-seeking over a gain domain and risk-averse over a loss domain was based on the evidence of concavity in the former domain and convexity in the latter domain of a value function, denoted by $v(x)$. The function also displayed a steeper slope over the loss domain than in the gain domain, highlighting that losses loom larger than gains. This reflects the gain required to compensate an individual for a one ringgit (RM1) loss. 
The second observation that individuals overweight small and underweight large probabilities suggests that their decision is determined by a non-linear probability weighting function, $w(p)$. It is assumed in CPT that individuals do not weigh the objective probability, $p$, linearly.

The robustness of the theory and the veracity of its predicted outcomes about the risk patterns have been demonstrated in several studies (see, for example, Abdellaoui, Bleichrodt, \& L'Haridon, 2008; Camerer \& Kunreuther, 1989; Harbaugh, Krause, \& Vesterlund, 2010). Past research has also found that the four-fold pattern of risk is a good predictor of risk behaviours when subjects are asked to report their willingness to pay for or accept a risky prospect (Gonzalez \& Wu, 1999; Harbaugh et al., 2010; Laury \& Holt, 2008).

\section{Experimental Design and Procedures}

\subsection{Subjects}

A total of 300 working adults were recruited to participate in a field experiment. Of the total, 176 or 59 percent of the subjects were Malays, 96 (32 percent) were Chinese and 28 (9 percent) were Indians. The ratio broadly reflects the ethnic composition of Peninsula Malaysia, with a slight overrepresentation of Chinese and Indians. The subject pool consisted of 150 men and 150 women ranging from 20 to 54 years of age.

The subjects were recruited from their workplaces, such as factories, offices, banks and retail shops. Prior approval was obtained from the respective managements to conduct the fieldwork during the lunch break in order to minimise work disruption. The subjects were randomly selected to participate in the study.

Six interviewers, who were undergraduates from a local public university, were recruited to conduct the field experiment. The interviewers were given training on the procedures to ensure that the explanations given to the subjects during the fieldwork were standardised and well-understood.

The interviewers spent, on average, 30 minutes to explain and guide each subject during the experiment. Every subject had the opportunity to receive a payoff ranging from RM10 to RM30, depending on his/her performance during the experiment. At the end of approximately six weeks, only 289 subjects (144 males and 145 females) had successfully completed the experiment. The other 11 subjects were dropped because they violated the rules of the game (see section on the two-choice lottery games below). Table 1 reports the breakdown of the subject pool based on ethnicity and age.

The subjects were asked about their education background during the recruitment to ensure that subjects are able to understand the instructions and procedures. Of the 289 subjects, 153 subjects had completed their tertiary education with a minimum diploma qualification in local universities. The remaining subjects had completed at least secondary education (equivalent to 11 years of education).

Of the total sample, 192 subjects earned an annual income above RM20,000 (USD5000), while the remaining 97 subjects earned below this amount. The majority were married (180 subjects). 
Table 1. Total number of subjects according to ethnicity and age

\begin{tabular}{lcrrrrrrr}
\hline Age & Malay & \multicolumn{1}{c}{$\%$} & Chinese & \multicolumn{1}{c}{$\%$} & Indian & $\%$ & Total & $\%$ \\
\hline $20-24$ & 37 & 21.5 & 14 & 15.2 & 4 & 16.0 & 55 & 19.0 \\
$25-29$ & 36 & 20.9 & 22 & 24.0 & 5 & 20.0 & 63 & 21.8 \\
$30-34$ & 29 & 16.9 & 13 & 14.1 & 4 & 16.0 & 46 & 15.9 \\
$35-39$ & 23 & 13.4 & 12 & 13.0 & 4 & 16.0 & 39 & 13.5 \\
$40-44$ & 17 & 9.9 & 11 & 11.9 & 2 & 8.0 & 30 & 10.4 \\
$45-49$ & 15 & 8.7 & 8 & 8.7 & 4 & 16.0 & 27 & 9.3 \\
$50-54$ & 15 & 8.7 & 12 & 13.0 & 2 & 8.0 & 29 & 10.0 \\
\hline Total & 172 & 100 & 92 & 100 & 25 & 100 & 289 & 100 \\
\hline
\end{tabular}

\subsection{The Two-Choice Lottery Games}

Thirty (30) two-choice lottery games were designed to elicit risk preferences of the subjects. One-half of the lotteries was designed to yield potential gain (i.e. gain domain) the other half was designed to yield potential loss (i.e. loss domain). In each lottery game, subjects could choose option A (lottery), which was a choice that involved risk, or option $B$, which was a choice with a guaranteed payoff. The lottery or option A was considered a risky choice as the potential gain or loss depended on probabilities that ranged from 5 percent, 20 percent, 50 percent, 80 percent and 90 percent. Option A is referred to as the risky choice or lottery throughout the rest of the paper. Table 2 shows one of the lottery games in the gain domain that was used in the experiment.

It was emphasised to the subjects that they were allowed to switch from option B to option $A$ (or vice versa) only once. If a subject exhibited inconsistency and switched between option $A$ and $B$ more than once, the subject was removed from the analysis. For example, if a subject chose option $B$ at first, when the guaranteed payoff was RM10 and switched to option $A$, when the guaranteed payoff was RM9, and then switched back to option B, when the guaranteed payoff was RM4, the choice was considered illogical. This is because the subject showed a willingness to take a risk when the guaranteed payoff was RM9, but not when the guaranteed payoff was RM4. A subject willing to take a risk when the guaranteed payoff was RM9 should be willing to do so for all guaranteed payoffs lower than RM9. Furthermore, in a choice between the guaranteed payoff of RM10 (option B) in the gain domain, and option A, which only held a 5 percent probability of winning, the logical choice would be the guaranteed payment of RM10 (option B), instead of option A. Therefore, subjects who chose option $A$, instead of $B$, for the first choice in the gain domain were removed from the analysis. The answers of 11 subjects who violated these two requirements were removed from the analysis.

After the subjects had made choices for all 30 lottery games, one of the lottery games was randomly selected from each of the gain and loss domains for the final payoff calculation. The calculation involved five steps as detailed in the following: 
Table 2. Sample lottery game in gain domain

\begin{tabular}{|c|c|c|c|c|}
\hline & \multirow{2}{*}{$\begin{array}{l}\text { Option A } \\
\text { (lottery) }\end{array}$} & \multicolumn{2}{|c|}{ Your choice } & \multirow{2}{*}{$\begin{array}{c}\text { Option B } \\
\text { (guaranteed payoff) } \\
\text { RM }\end{array}$} \\
\hline & & A & $B$ & \\
\hline 1 & \multirow{20}{*}{$\begin{array}{l}\text { Profit of RMX with } \\
\text { probability y and profit of } \\
\text { RMO with probability (1-y) }\end{array}$} & & & 10.00 \\
\hline 2 & & & & 9.50 \\
\hline 3 & & & & 9.00 \\
\hline 4 & & & & 8.50 \\
\hline 5 & & & & 8.00 \\
\hline 6 & & & & 7.50 \\
\hline 7 & & & & 7.00 \\
\hline 8 & & & & 6.50 \\
\hline 9 & & & & 6.00 \\
\hline 10 & & & & 5.50 \\
\hline 11 & & & & 5.00 \\
\hline 12 & & & & 4.50 \\
\hline 13 & & & & 4.00 \\
\hline 14 & & & & 3.50 \\
\hline 15 & & & & 3.00 \\
\hline 16 & & & & 2.50 \\
\hline 17 & & & & 2.00 \\
\hline 18 & & & & 1.50 \\
\hline 19 & & & & 1.00 \\
\hline 20 & & & & 0.50 \\
\hline
\end{tabular}

Note: RMX refers to the amount of monetary reward; it ranges from RM10 (USD2.50), RM20 (USD5) and RM30 (USD7.50). The parameter y refers to probability, from 5\%, 20\%, 50\%, $80 \%$ and $90 \%$. Subjects were asked to play a lottery with three different rewards, with five different probability levels. Therefore, 3 monetary rewards $x 5$ probability levels = 15 lottery games in the gain domain. The same applies to lotteries in the loss domain.

STEP 1: Generate two random numbers from 1 to 15 to decide on which lottery game is to be chosen from each of the loss and gain domains

For example, if the first number generated is 3 , Lottery game 3 from the gain domain is chosen. If the second number generated is 9 , Lottery game 9 from the loss domain is chosen. 
STEP 2: Generate two random numbers from 1 to 20 to decide on which choice in the lottery game chosen in step 1 above is to be selected

For example, if the first number generated is 15 , choice number 15 in lottery game 3 is selected. If the second number generated is 4 , choice number 4 in lottery game 9 is selected.

\section{STEP 3: If the choices in the two lottery games are option B (guaranteed amount)}

If the subject chose option B in choice number 15 in lottery game 3 , he or she would be paid the guaranteed amount as stated in the lottery. In the loss domain, if the subject chose option B in choice number 4 in lottery game 9 , the subject earns the negative payoff. For example, the guaranteed payoff in option B in lottery game 3 for choice number 15 is RM9, and the guaranteed negative payoff in lottery game 9 is RM25.50. The subject, therefore, earns RM9 in the gain domain and loses RM25.50 in the loss domain.

\section{STEP 4: If the choice in the two lottery games is option A (risky choice)}

Option A in all lottery games involves risk. Choice number 15 in option A in lottery game 3 carries a 5 percent probability of winning RM30 and a 95 percent probability of winning nothing. Choice number 4 in lottery game 9 has a 50 percent probability of losing RM30 and 50 percent probability of losing nothing. To decide on the payoff in the risky choice, the experimenter must generate two random numbers from 1 to 100. If the first number generated is between 1 and 5, the subject earns RM30; if the number generated is 6 to 100 , the subject earns RM10. If the second number generated is between 1 and 50 the subject loses RM30 and if it is 51 to 100, the subject loses nothing.

\section{STEP 5: Final payoff calculation}

The final payoff of the subjects was calculated based on the difference between the positive payoff in the gain domain and the negative payoff in the loss domain. Following the example above, suppose option B was chosen in both games, then the final payoff will be $[\mathrm{RM9}+(-25.50)=-\mathrm{RM} 16.50]$. In the circumstances when the final payoff is less than RM10, the subject will be paid a minimum payoff of RM10. This condition, however, was not revealed to the subjects at the beginning of the experiment.

It is possible that the amount of cash in each participant's pocket may influence how they make decisions with respect to losses since participants do not know that they will not have to take money out of their pocket to pay the researchers. This would bias our results if participants in a given ethnic group have very little cash in hand or are more likely to feel embarrassed if they find themselves in such a situation ${ }^{2}$. However, since all participants were drawn randomly without regard to their income status, there are likely to be variations in income within each ethnic group. In other words, there is no reason to expect a systematic bias based on income to arise from any particular ethnic group.

2 This point was raised by a referee. 


\section{Results}

This section reports the risk tolerance based on the difference between CE (i.e. certainty equivalence) and EP (i.e. expected payoff) of a lottery game; a subject is classified as risk-seeking if $C E>E P$, risk-averse if $C E<E P$ and risk neutral if $C E=E P$. The value of CE was calculated using formula (1) below:

$$
C E=\frac{(x 1+x 2)}{2}
$$

CE was calculated when the subjects switched their option from $A$ to $B$ or vice versa. For example, using the lottery game in Table 2, when a subject switched from option B to option A when the guaranteed payoffs were RM5 and RM4.50, respectively, the CE of the subject is $=\frac{(\mathrm{RM} 5+\mathrm{RM} 4.50)}{2}=\mathrm{RM} 4.75$. This means the value of the risky option or the lottery (option A) is less than RM5 but more than RM4.50. However, if a subject chose option $B$ from the first choice until the last choice, the CE was 0 . This is because the perceived value of the lottery (option A) is less than RM0.50. Therefore, subjects with higher $\mathrm{CE}$ values are considered more risk-seeking than subjects with lower CE values.

We calculate the expected payoff (EP) of every lottery game using the following formula (2) below:

$$
E P=p(X)+(1-p)(Y)
$$

where $p$ denotes the probability of payoff " $X$ " occurring while $1-p$ denotes the probability of payoff " $Y$ " occurring. For example, in a lottery with payoff RM10 with probability 0.05 and RM0 with probability 0.95 , the EP $=0.05(10)+0.95(0)=\mathrm{RM0.50}$.

Table 3 shows the categorisation according to the three ethnic groups for all games in the gain domain. It is clear from the table that the majority of subjects were risk seekers in games with low probabilities (e.g. lottery games L1, L2 and L3 with probability 0.05 , and lottery games L4, L5 and L6 with probability 0.20 ). For each ethnic group, the number of subjects in column CE $>E P$, who valued the game higher than its expected payoff, was higher than in columns CE < EP and CE = EP. For example, there were 144 Malay subjects who valued the game $L 1(10,0.05 ; 0,0.95)$ higher than its expected payoff compared to 28 subjects who valued it to be less than the expected payoff (CE < EP). However, when the probabilities were larger at 0.80 and 0.95 from lottery games 10 to 15 , the risk behaviour reversed with the majority of subjects becoming risk averse. In these lottery games, the majority of subjects preferred a guaranteed payoff to taking a risk.

We look next at risk tolerance in the loss domain. Here subjects were faced with two choices: a guaranteed negative payoff or a lottery with a negative payoff. We wanted to see if the subject preferred a guaranteed loss to the lottery or option A (in which case he is risk-averse) or choose the lottery option to reduce the guaranteed loss (in which case he is risk seeking). As in the gain domain, if CE > EP, a subject is categorised as risk-seeking, risk-averse if CE $<$ EP and risk neutral if CE $=$ EP. Table 4 reports the risk tolerance among three ethnic groups in the loss domain. It is clear that 
Kean-Siang Ch'ng and Suresh Narayanan

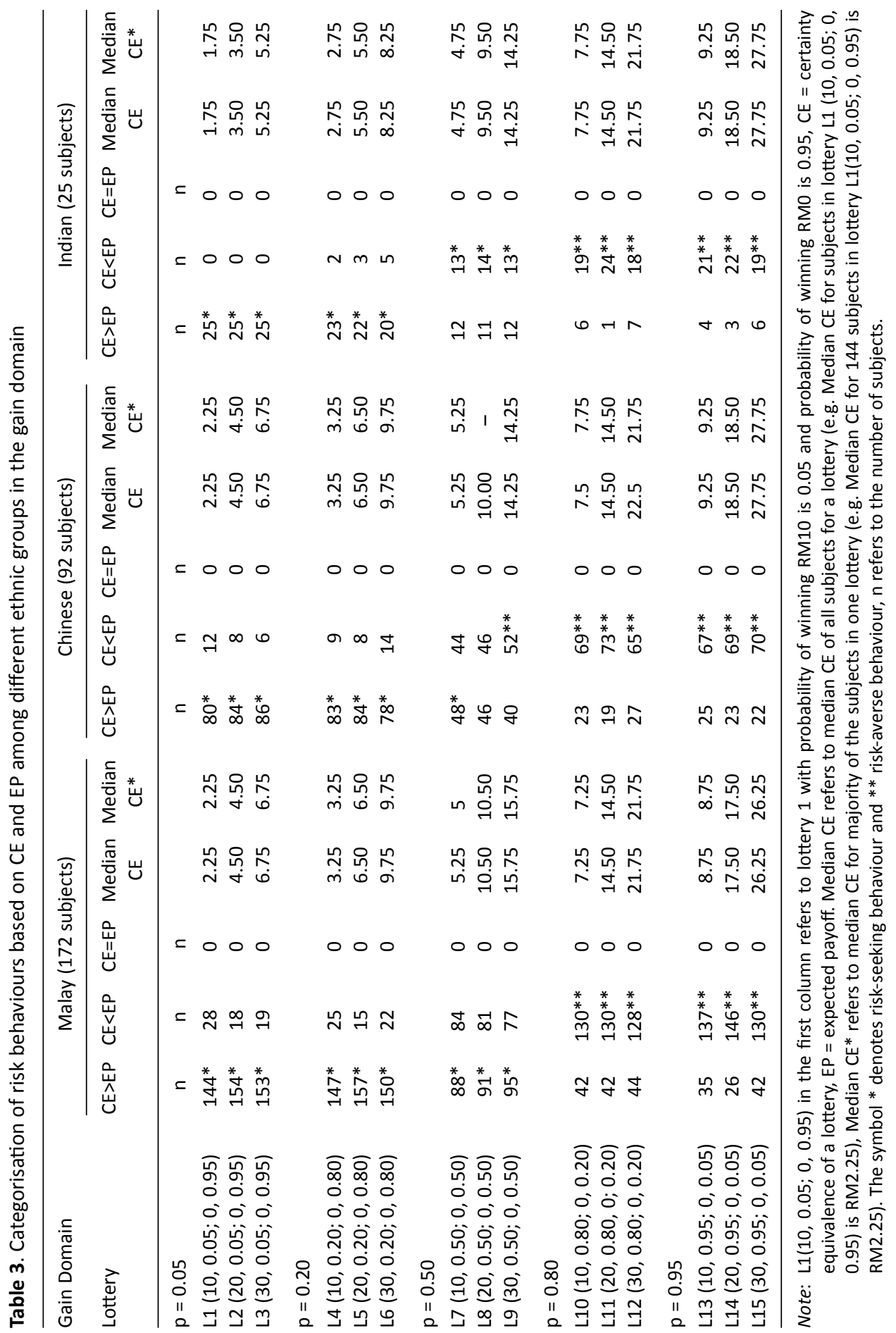


Differences in Risk Preferences of the Main Ethnic Groups in Peninsular Malaysia

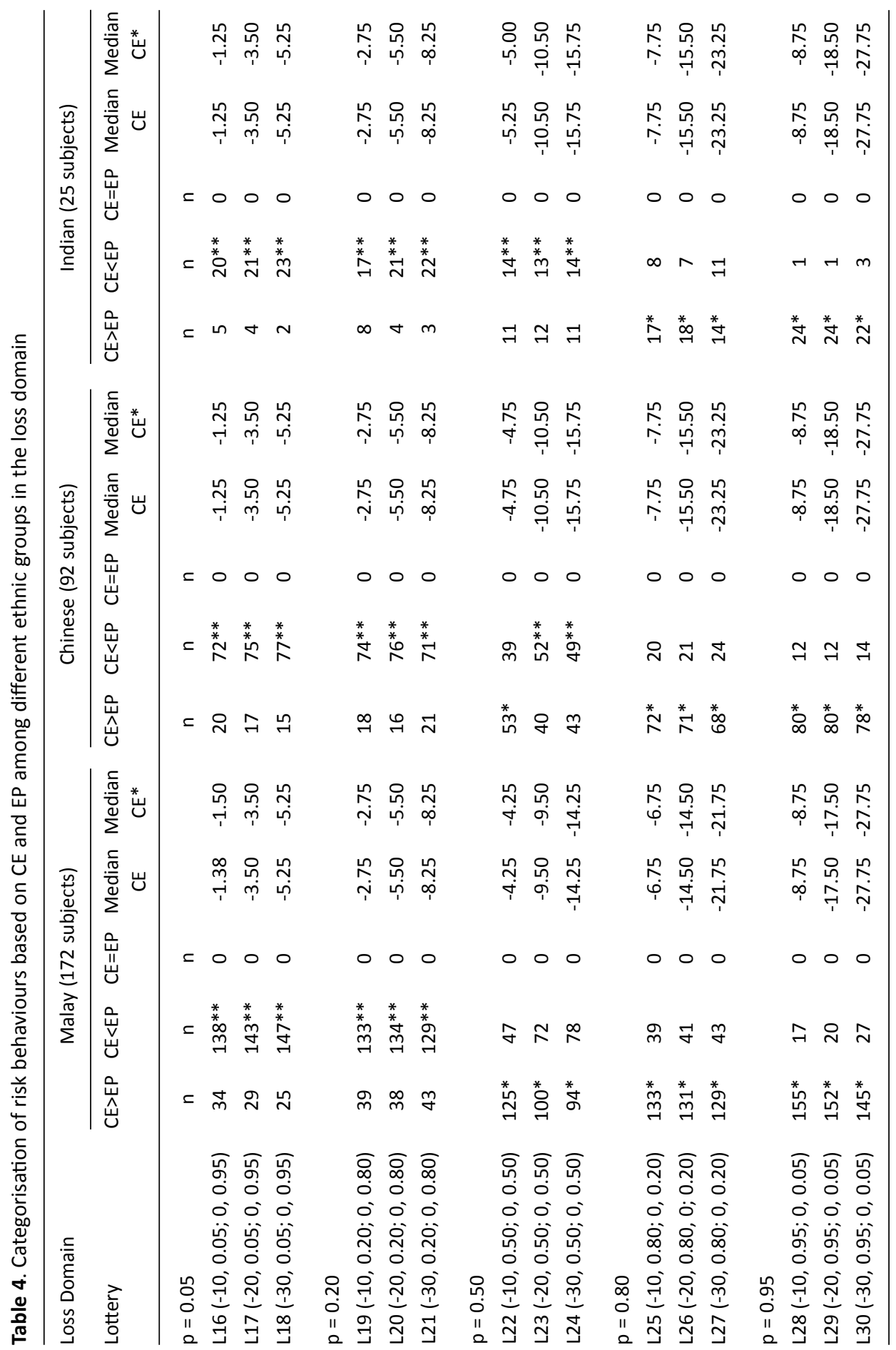


in games with low probabilities, such as in games 16 to lottery 21 (L16 to L21 in the table), more than half of all subjects within each ethnic group were risk averse. This means they chose guaranteed loss option over the lottery to avoid the risk of losing more. This was the case even though the expected loss from the lottery was lower than the guaranteed loss. In games with large probabilities of losing, such as games 25 to 30 ( $L 25$ to L30 in the table), the majority within each ethnic group became risk seeking. This can occur only when subjects chose lotteries over the guaranteed payoff in the hope that the lottery might reduce the odds of losing, although the expected loss from playing lotteries was higher than the guaranteed payoff.

Thus far, the risk behaviours revealed in both Tables 3 and 4 conform to the hypothesis that subjects are risk-seeking when the probability of winning is low and risk-averse when the probability of winning is large. The risk behaviour is reversed in the loss domain when subjects become risk averse when the probability of losing is low and risk-seeking when the probability of losing is large.

Next, we compare risk behaviour among the ethnic groups separately with low and high probabilities in both domains. The certainty equivalence (CE) approximates the perceived value of a lottery. It allows us to compare risk tolerance among ethnic groups based on this value. In low probability lotteries (i.e. lotteries 1 to 6 ), the average of the median CE for Malays and Chinese was RM5.5 each, and the average of the median CE for Indians was RM4.5. Based on the Wilcoxon signed-rank test, the difference is statistically significant $(z=-6.791, p$-value $=0.0000)$. In high probability lotteries (i.e. lotteries 10 to 15), the average of the median CE for Malays was RM16, which is significantly lower than for the Chinese and Indian groups who had the same average of the median CE of RM16.60 ( $z=-7.666, p$-value $=0.0000)$. Hence, based on the average of the median $\mathrm{CE}$, it is clear that the Chinese and Indians were more optimistic and perceived a positive risky prospect as more valuable when compared to Malays when the probability of winning was high. But in lotteries with low probabilities, Malays and Chinese were more risk-seeking than Indians.

In the loss domain, the average of the median CE in low probability lotteries (i.e. lotteries 16 - 21) for Chinese and Indians was -RM4.42 each, which is marginally higher than that of their Malay counterparts -RM4.46. However, when they were faced with a high probability of losing (i.e. lotteries $25-30$ ), Malays became significantly more riskseeking with an average median CE of -RM16.17, as compared to Chinese and Indians (average median CE -RM16.92) $(z=8.80, p$-value $=0.0000)$.

In conclusion, based on the values of certainty equivalence, in low probability lotteries, Chinese and Malays were more risk seeking than Indians, but in high probability lotteries, Chinese and Indians were more risk seeking than Malays. In the loss domain high probability lotteries, Malays were more risk seeking than both Chinese and Indians.

The risk behaviours revealed by the certainty equivalence gives an idea about overall individual risk tolerance but does not show how subjects perceive payoff/ outcomes or probability of a lottery. We next investigate how different ethnic groups weighted outcome/payoff of a lottery.

Table 5 reports the ratio between CE in the gain domain and CE in the loss domain for a symmetrical lottery. From the table, for example, L1 vs L16 gives the ratio between 
Table 5. Ratio of CE gain and CE loss, by ethnic groups

\begin{tabular}{llll}
\hline Symmetric payoff & Malay & Chinese & Indian \\
\hline$p=0.05$ & & & \\
L1 vs L16 & 1.64 & 1.80 & 1.40 \\
L2 vs L17 & 1.29 & 1.29 & 1.00 \\
L3 vs L18 & 1.29 & 1.29 & 1.00 \\
$p=0.20$ & & & \\
L4 vs L19 & 1.18 & 1.18 & 1.00 \\
L5 vs L20 & 1.18 & 1.18 & 1.00 \\
L6 vs L21 & 1.18 & 1.18 & 1.00 \\
$p=0.50$ & & & \\
L7 vs L22 & 1.24 & 1.11 & 0.90 \\
L8 vs L23 & 1.11 & 0.95 & 0.90 \\
L9 vs L24 & 1.11 & 0.90 & 0.90 \\
$p=0.80$ & & & \\
L10 vs L25 & 1.07 & 0.97 & 1.00 \\
L11 vs L26 & 1.00 & 0.94 & 0.94 \\
L12 vs L27 & 1.00 & 0.97 & 0.94 \\
$p=0.95$ & & & \\
L13 vs L28 & 1.00 & 1.06 & 1.06 \\
L14 vs L29 & 1.00 & 1.00 & 1.00 \\
L15 vs L30 & 0.95 & 1.00 & \\
\hline
\end{tabular}

median CE lottery game 1 (RM10, 0.05; RM0, 0.95) and median CE lottery game 16 (-RM10, 0.05; RM0, 0.95). The sensitivity to loss than gain can be derived from the ratio; if the ratio is higher than one, it means more than RM1 in gain is required to compensate a RM1 loss, and if it is lower than one, less than RM1 in gain is required to compensate for a RM1 loss; finally, subjects are indifferent if the ratio is one. This asymmetry in value of gain and loss (i.e. if the ratio is more than one) means that a loss is assigned a greater value than a gain of an identical amount; in other words, when loss hurts more than the good a gain gives, subjects are likely to take a greater risk to avoid a potential loss than ensure a gain.

The data in Table 5 indicate that both Chinese and Malays have a higher ratio relative to Indians (Indian vs Chinese, $z$-value $=-2.704$ and $p$-value $=0.0068$; Indian vs Malays, $z$-value $=-3.101$ and $p$-value $=0.0019)$, but the difference between the Chinese and Malays, however, was not significantly different. When comparisons are made based on different probability scales, the Malays appear more willing to take marginally higher risk in order to reduce loss than their Chinese counterparts in the case of lotteries with probabilities exceeding 0.5 (z-value $=1.78$ and $p$-value $=0.0750)$. This helps to explain why both Chinese and Indian groups were more risk-averse than their Malay counterparts in the loss domain as was observed earlier.

The pattern of probability evaluation by ethnic groups is examined next. Table 6 reports the probability evaluation by each ethnic group according to different probabilities and Figure 1 plots the weighted probability $(w p)$ against objective probability $(p)$. 
Table 6. Weighted probability in gain and loss domains for three ethnic groups

\begin{tabular}{|c|c|c|c|c|c|c|c|c|c|}
\hline \multicolumn{6}{|c|}{ Gain domain } & \multicolumn{4}{|c|}{ Loss domain } \\
\hline \multirow[t]{5}{*}{ Payoff (RM) } & & Malay & Chinese & Indian & Payoff (RM) & & Malay & Chinese & Indian \\
\hline & $p$ & $w p 1$ & $w p 2$ & wp3 & & $p$ & wp4 & wp5 & wp6 \\
\hline & 0 & 0 & 0 & 0 & & 0 & 0 & 0 & 0 \\
\hline & 0.05 & 0.1750 & 0.1721 & 0.1163 & & 0.05 & 0.1155 & 0.1089 & 0.1160 \\
\hline & 0.20 & 0.3481 & 0.3494 & 0.2869 & & 0.20 & 0.2733 & 0.2734 & 0.2886 \\
\hline \multirow[t]{7}{*}{10} & 0.50 & 0.5484 & 0.5555 & 0.5207 & -10 & 0.50 & 0.4906 & 0.5056 & 0.5254 \\
\hline & 0.80 & 0.7341 & 0.7441 & 0.7459 & & 0.80 & 0.7116 & 0.7355 & 0.7513 \\
\hline & 0.95 & 0.8742 & 0.8825 & 0.8997 & & 0.95 & 0.8766 & 0.8954 & 0.9033 \\
\hline & 1 & 1 & 1 & 1 & & 1 & 1 & 1 & 1 \\
\hline & 0 & 0 & 0 & 0 & & 0 & 0 & 0 & 0 \\
\hline & 0.05 & 0.1862 & 0.1707 & 0.1228 & & 0.05 & 0.1340 & 0.1243 & 0.1243 \\
\hline & 0.20 & 0.352 & 0.3408 & 0.2866 & & 0.20 & 0.2932 & 0.3028 & 0.3028 \\
\hline \multirow[t]{7}{*}{20} & 0.50 & 0.5396 & 0.5400 & 0.5065 & -20 & 0.50 & 0.4994 & 0.5402 & 0.5402 \\
\hline & 0.80 & 0.7166 & 0.7271 & 0.7238 & & 0.80 & 0.7058 & 0.7607 & 0.7607 \\
\hline & 0.95 & 0.8572 & 0.8700 & 0.8826 & & 0.95 & 0.8655 & 0.9068 & 0.9068 \\
\hline & 1 & 1 & 1 & 1 & & 1 & 1 & 1 & 1 \\
\hline & 0 & 0 & 0 & 0 & & 0 & 0 & 0 & 0 \\
\hline & 0.05 & 0.175 & 0.1635 & 0.1228 & & 0.05 & 0.1228 & 0.1243 & 0.1243 \\
\hline & 0.20 & 0.3481 & 0.3346 & 0.2866 & & 0.20 & 0.2866 & 0.3028 & 0.3028 \\
\hline \multirow[t]{4}{*}{30} & 0.50 & 0.5484 & 0.5384 & 0.5065 & -30 & 0.50 & 0.5065 & 0.5402 & 0.5402 \\
\hline & 0.80 & 0.7341 & 0.7301 & 0.7238 & & 0.80 & 0.7238 & 0.7607 & 0.7607 \\
\hline & 0.95 & 0.8742 & 0.8744 & 0.8826 & & 0.95 & 0.8826 & 0.9068 & 0.9068 \\
\hline & 1 & 1 & 1 & 1 & & 1 & 1 & 1 & 1 \\
\hline
\end{tabular}

Note: The variables wp1, wp2 and wp3 are the weighted probabilities for Malays, Chinese and Indians, respectively, in the gain domain. Similarly, wp4, wp5 and $w p 6$ are the weighted probabilities for Malays, Chinese and Indians, respectively, in the loss domain. The variable $p$ is the objective probability.

All the diagonal lines in Figure 1 depict all points when the weighted probability $w(p)$ equals the objective probability $(p)$. When $w(p)$ lies above or below the diagonal line, it indicates overweighting or underweighting the probability, respectively.

It can be observed from Figure 1 that subjects in all three ethnic groups over weighted small and underweighted large probabilities. This conforms with results reported in the literature (Abdellaoui, 2000; Abdellaoui et al., 2008; Camerer \& Ho, 1994; Gonzalez \& Wu, 1999).

The details of probability weighting behaviour for each level of probability can be seen from Table 6 . As reported in the table, in the gain domain, and across almost all t payoffs (i.e. from RM10, RM20 and RM30), Malays perceived low probability lotteries (i.e. $p=0.05$ and $p=0.2$ ) more optimistically than the other two groups. For example, in the lottery with a payoff of RM10, the objective probability of 0.05 was weighted as 0.175 by Malays as compared to 0.1721 by Chinese and 0.1163 by Indians. But 


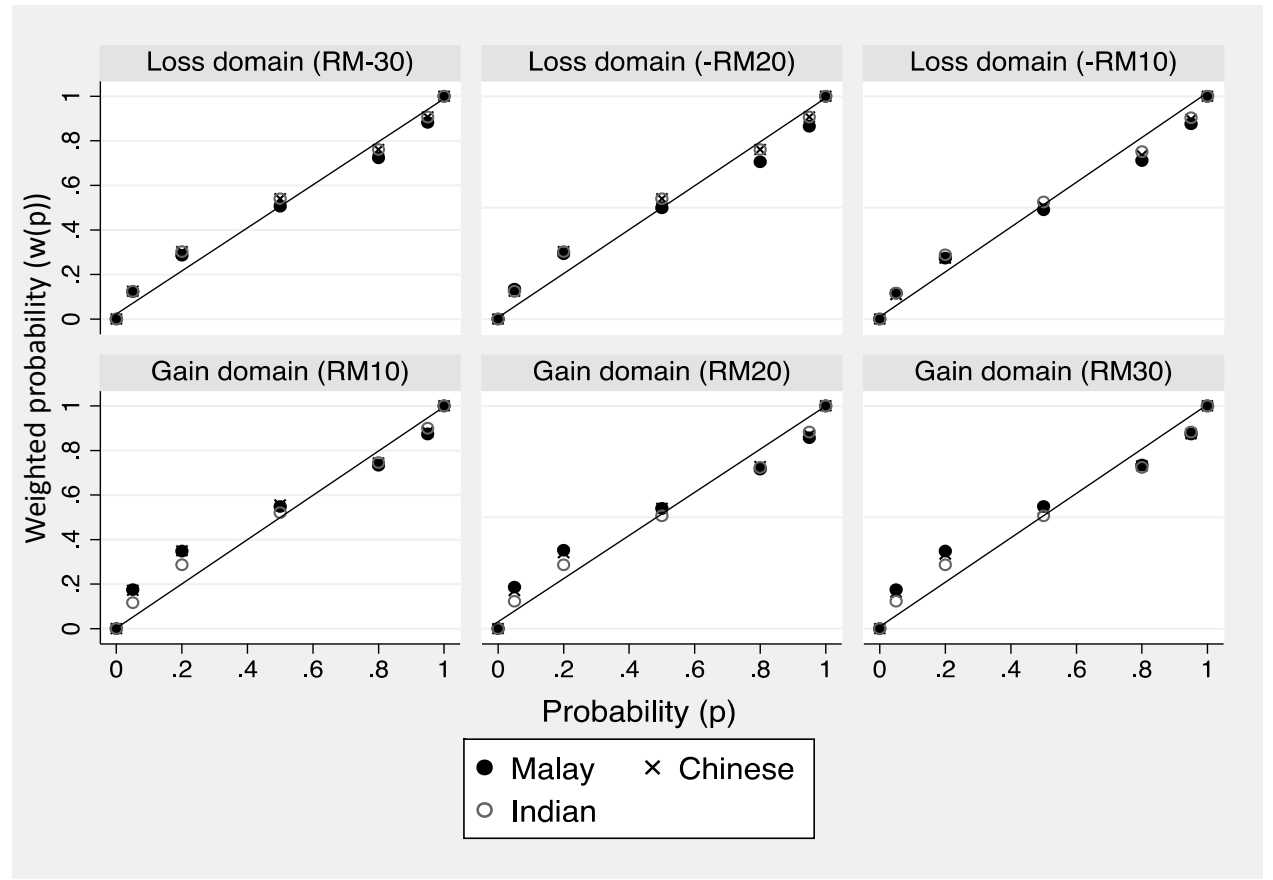

Figure 1. Probability weighting curves based on racial groups

when the probability of winning a lottery became larger (such as when it exceeds 0.5), Malays weighted the chances of winning to be lower than the other two groups. When comparing the probability weighting of Chinese and Indians, the former evaluated small probabilities $(p=0.05$ and $p=0.2$ ) of winning more optimistically than Indians ( $z$-value $=$ $7.72, p$-value $=0.0000$ ), but the difference was not significant when the probabilities exceeded 0.5 .

In the loss domain, on average, the Chinese and Indians weighed the probability of losing higher than their Malay counterparts. In other words, the former two groups perceived the chances of losing as being higher and therefore became more intolerant to risk in the loss domain.

Overall, the distinctive probability and value functions displayed by the groups explain their different risk tolerance levels. Based on the value function (which measures the ratio between gain and loss), on average, Malays equate losing RM1 to a loss of RM1.49, while the Chinese equate it to a loss of RM1.12 and Indians to a loss of RM1.02. This implies that Malays are the most risk-seeking in the loss domain, followed by Chinese and Indians. In evaluating probability in the gain domain, Malays perceived small chances of winning more optimistically and large chances of winning less optimistically than the other two groups. Whereas in the loss domain, Malays become more risk-seeking because they under weigh their chances of losing a lottery, as compared to the other two groups. 


\section{Discussion and Conclusions}

Much of the economic success of the Chinese has been commonly attributed to their tendency to be more risk seeking. Past research has relied on the immigrant background of the Chinese to explain this trait among them. Similarly, the taboo against gambling in Islam has been suggested as a possible factor to explain the perceived aversion to risk among Malays. While our experiment cannot explain differences in risk behaviour among the three ethnic groups, it can observe these differences, if they exist. To our knowledge, there has been no objective study examining how each ethnic group perceives and evaluates risk in a controlled environment.

Our results do not lend support to the general impression that Chinese are risk takers and Malays are risk-averse. In fact, all ethnic groups behave in a manner consistent with the cumulative prospect theory, both in the gain and loss domains, though they differ with respect to degree.

In the gain domain, when the probability of winning is low, all ethnic groups are risk seeking but compared to the Chinese, the Malays are more risk seeking and the Indians are the least risk seeking ${ }^{3}$. In the gain domain, on the other hand, when the probability of winning is high, all ethnic groups become risk averse but the Malays appear to be the most risk averse and the Chinese the least risk averse. These results indicate that, compared to the other ethnic groups, Malays become most risk seeking when the probability of winning is low and become the most risk averse when the probability of winning is high. This implies that higher Malay participation can be expected in ventures with low probabilities of winning and a lower Malay participation might be expected in ventures with high probabilities of gains, relative to the other groups.

In the loss domain, across all probabilities of loss (high or low), all ethnic groups are risk averse but the Malays appear to be the least averse to risk relative to the other ethnic groups. This implies that higher Malay participation can be expected in ventures with high probabilities of losing and a lower Malay participation might be expected in ventures with lower probabilities of losses, relative to other groups.

Additionally, the CE ratio analysis shows that a ringgit loss hurts the Malays more than the satisfaction from a ringgit gain. Therefore they are likely to take greater risks to avoid a ringgit loss than to get a sure gain of one ringgit, than the other races. This suggests that Malays have to be persuaded with larger gains to participate in risky ventures as compared to Chinese or Indians.

To conclude, differences in tolerance to risk among the three ethnic groups exist but in degree rather than in form. Thus, broad generalisations that the Chinese are risk takers and the Malays are risk averse need to be further qualified in the light of our experiments. However, the results of our experiments do suggest the differences in the degree of risk tolerance among the Chinese and Malays could be a factor in accounting for the differences in their wealth but our experiments can neither directly support nor reject this hypothesis.

3 While we cannot assert this with certainty, it is possible that the lack of social protection from both the government and community groups may explain the behaviour of Indians noted above. We owe this point to one of the reviewers of the paper. 


\section{References}

Abdellaoui, M. (2000). Parameter-free elicitation of utility and probability weighting functions. Management Science, 46(11), 1497-1512.

Abdellaoui, M., Bleichrodt, H., \& L'Haridon, O. (2008). A tractable method to measure utility and loss aversion under prospect theory. Journal of Risk and Uncertainty, 36(3), 245-266. https:// doi.org/10.1007/s11166-008-9039-8

Akgüç, M., Liu, X., Tani, M., Zimmermann, K.F. (2016). Risk attitudes and migration. China Economic Review, 37(C), 166-176. https://doi.org/10.1016/j.chieco.2015.12.004

Camerer, C.F., \& Ho, T.H. (1994). Violations of the betweenness axiom and nonlinearity in probability. Journal of Risk and Uncertainty, 8(2), 167-196. https://doi.org/10.1007/ BF01065371

Camerer, C.F., \& Kunreuther H. (1989). Decision processes for low probability events: policy implications. Journal of Policy Analysis and Management, 8(4), 565-592. https://doi. org $/ 10.2307 / 3325045$

Gonzalez, R., \& Wu, G. (1999). On the shape of the probability weighting function. Cognitive Psychology, 38(1), 129-166. https://doi.org/10.1006/cogp.1998.0710

Harbaugh, W.T., Krause, K., \& Vesterlund, L. (2010). The fourfold pattern of risk attitudes in choice and pricing tasks. The Economic Journal, 120(545), 595-611. https://doi.org/10.1111/j.14680297.2009.02312.x

Jackson, R.N. (1961). Immigrant Labour and the Development of Malaya, 1786-1920. Kuala Lumpur: Government Press.

Lai, F.S., Chong, S.C., Sia, B.K., \& Ooi, B.C. (2010). Culture and consumer behavior: Comparisons between Malays and Chinese in Malaysia. International Journal of Innovation, Management and Technology, 1(2), 180-185.

Laury, S.K., \& Holt, C.A. (2008). Further reflections on the reflection effect. In J.C. Cox \& G.W. Harrison (Eds.), Risk aversion in experiments (Research in experimental economics, vol. 12). Bingley, UK: JAI Press.

Nielsen, J.S., Bech, M., Christensen, K., Kiil, A., \& Hvidt, N.C. (2017). Risk aversion and religious behaviour: Analysis using a sample of Danish twins. Economics \& Human Biology, 26(August), 21-29. https://doi.org/10.1016/j.ehb.2017.01.004

Satyanarayana, A. (2002). "Birds of passage": Migration of South Indian labourers to Southeast Asia. Critical Asian Studies, 34(1), 89-115. https://doi.org/10.1080/146727102760166617

Starmer, C. (2000). Developments in non-expected utility theory: The hunt for a descriptive theory of choice under risk. Journal of Economic Literature, 38(2), 332-382.

Starmer, C., \& Sugden, R. (1989). Violations of the independence axiom in common ratio problems: An experimental test of some competing hypotheses. Annals of Operations Research, 19(1), 79-102. https://doi.org/10.1007/BF02283515

Tversky, A., \& Kahneman, D. (1992). Advances in prospect theory: Cumulative representation of uncertainty. Journal of Risk and Uncertainty, 5(4), 297-323. https://doi.org/10.1007/ BF00122574 
